\title{
EQUTVALENT CIRCUIT ANALYSIS OF THE RHIC INJECTION KICKER
}

\author{
H. Hahn*and A. Ratti ${ }^{\dagger}$, Brookhaven National Laboratory, Upton, New York 11973
}

RECEIVED

\section{Abstract}

The RHIC injection kicker is built as a travelling wave structure in order to assure the required $95 \mathrm{nsec}$ risetime in the deflection strength. The kicker is constructed from 14 cells, each $7.5 \mathrm{~cm}$ long, with alternating ferrite and highpermittivity dielectric sections. The cell structure permits an analysis of the electrical properties of the kicker using lumped $L, C$, and $R$ circuit elements. Their values are obtained directly from impedance measurements of the fulllength kicker, the inductance and shunt capacitance values by measuring the input impedance at $1 \mathrm{MHz}$ with the output shorted and open, respectively. A lossy series resonance circuit in each cell is found to reproduce the measured input impedance of the terminated kicker up to $\sim 100$ $\mathrm{MHz}$. The validity of the equivalent circuit was confirmed by comparing the measured output current pulse shape time with that computed by the P-Spice program.

\section{INTRODUCTION}

The RHIC injection kicker was conceived as a transmission line magnet in order to achieve the required rise time of $<95$ nsec. ${ }^{1}$ The kicker is configured from ferrite and dielectric blocks as a " $C$ " type magnet with its geometry shown in Fig. 1. The deflecting properties of the kicker are dominated by the magnetic field and thus by the geometry and properties of the ferrite blocks. The nickel-zinc ferrite (CMD-5005 by Ceramic Magnetics) has a high permeability and resistivity for use at frequencies up to $\sim 100 \mathrm{MHz}$. Altrough in principle continuous at the side, the ferrite must be subdivided to limit eddy current effects. The capacity required to achieve the transmission line behavior is predominantly provided by the dielectric ceramic blocks, a sintered mixture of magnesium and calcium titanate (MCT125 by Trans-Tech) with high dielectric constant, $\epsilon=125$, to achieve the characteristic impedance of $25 \Omega$. The contribution to the capacity from the ceramic beam tube is negligible, and for convenience sake, all kicker measurements were made without it.

The original kicker design was based on an equivalent circuit analysis of a low-pass filter with lumped $L$ and $C$ elements. ${ }^{2}$ In a subsequent paper, the kicker was treated as a transmission line with uniform, albeit anisotropic properties in order to establish a better correlation of geometrical with electrical parameters. ${ }^{3}$ In an attempt to estimate the current rise time from the low-pass band width, the kicker was treated as a cascaded chain of transmission lines

\footnotetext{
* Work performed under the auspices of the U.S. Deparment of Energy
}

' Present address: LBNL, Berkeley, CA 94720

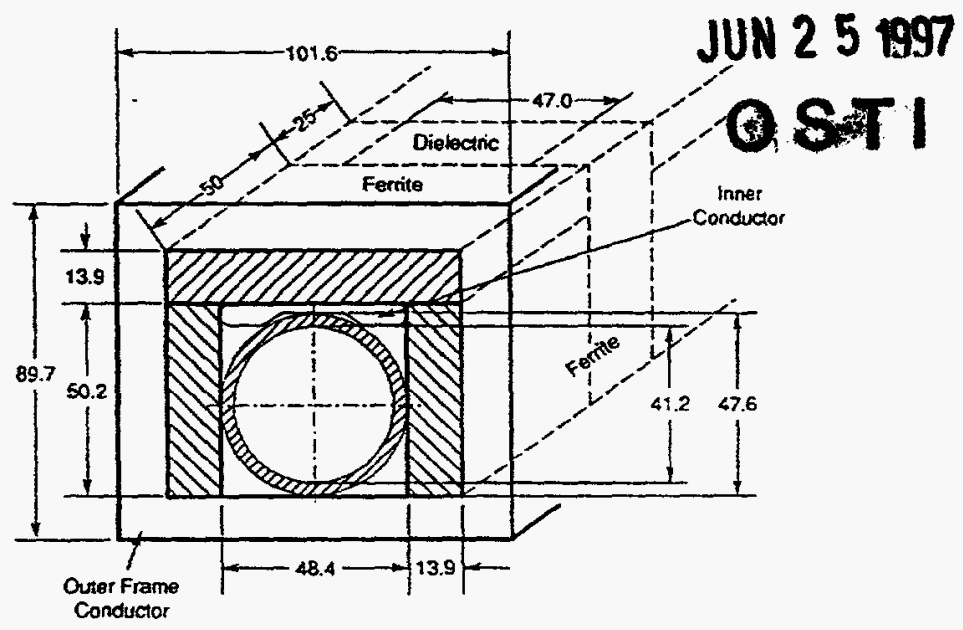

Figure 1: RHIC Injection Kicker Configuration.

with different characteristic impedances and propagation velocities. ${ }^{4}$ Although useful, the simple equivalent circuits presented so far are limited and do not allow a reliable prediction of the kicker performance resulting from engineering changes or from varied operational conditions, such as the mismatched $20 \Omega$ termination used in the Sextant Test. In this paper, an equivalent circuit for a generalized lowpass filter with lumped elements is presented, which was obtained from direct measurements of the kicker. The PSpice program was then used to simulate the kicker performance and the comparison with experimental data showed fully satisfactory agreement. ${ }^{5}$

\section{EQUIVALENT CIRCUIT}

The RHIC injection kicker is constructed as a low-pass filter with 14 cells, each $7.5 \mathrm{~cm}$ long, with alternating ferrite and high-permittivity dielectric sections, thereby approximating a transmission line magnet. The cell structure permits an analysis of the electrical properties of the kicker using an equivalent circuit with lumped $L, C$, and $R$ elements. Their values are obtained directly from input impedance measurements of the full-size kicker in the frequency range up to $\sim 100 \mathrm{MHz}$. Discussed here in detail is the production kicker \#5, in which the MCT-125 dielectric blocks are used.

The inductance is obtained from the input impedance at $1 \mathrm{MHz}$ with the output port shorted. The total inductance was measured to be $1.59 \mu \mathrm{H}$, resulting in $106 \mathrm{nH}$ for each of the 15 series inductors. At frequencies below the $\lambda / 4$ resonance, $4.757 \mathrm{MHz}$, the input impedance of the shorted 
kicker is given by $Z_{\text {in }}=Z_{K} \tan \left(\frac{1}{2} \pi f / f_{\lambda / 4}\right)$, from which follows the characteristic impedance of the kicker as $Z_{K} \approx$ $26 \Omega$.

The capacitance is obtained from the input impedance at $1 \mathrm{MHz}$ with the output port open. The total capacitance was $1.99 \mathrm{nF}$, resulting in $\sim 140 \mathrm{pF}$ for each of the 14 dielectric blocks. The measured input impedance of the kicker terminated with the nominal $25 \Omega$ is shown in Fig. 2 . The pronounced resonance at $64 \mathrm{MHz}$ can be represented by a lossy series resonance. This resonance is associated with eddy currents in the ferrite side blocks, as established by a series of measurements with side blocks of different lengths. The circuit elements, and in particular the damping resistors, were adjusted to render the strength of the resonances in the open and shorted condition.
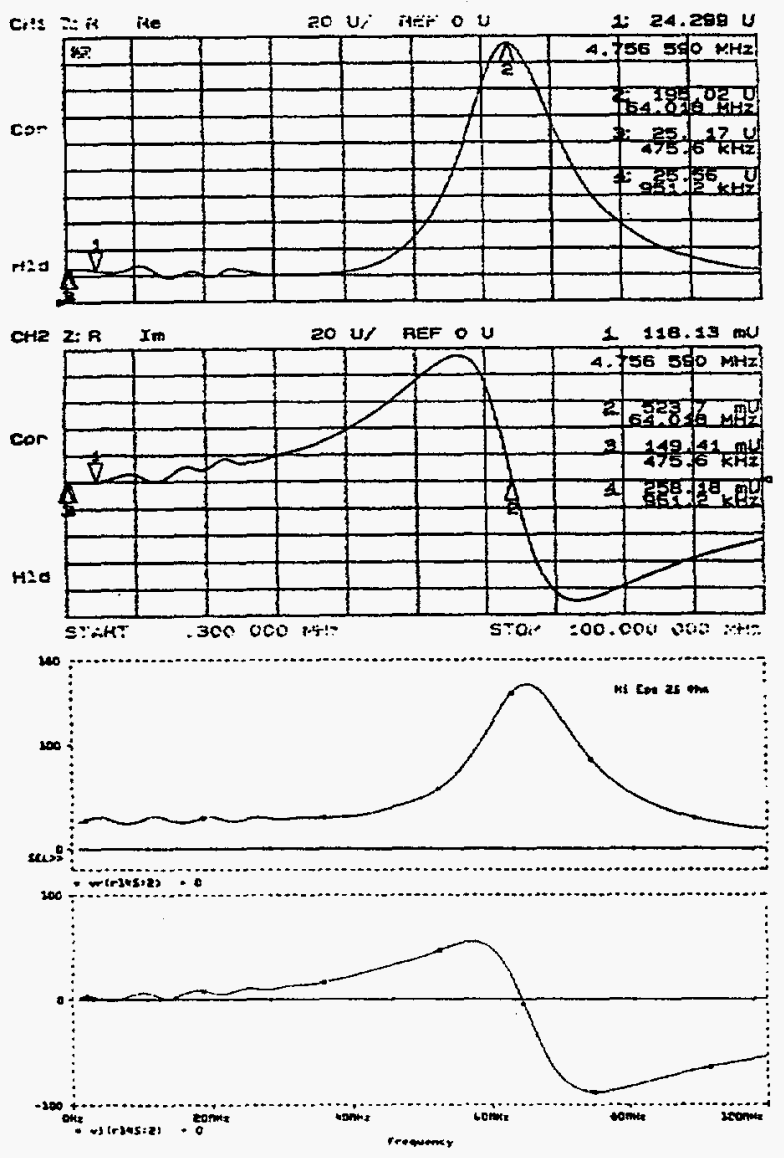

Figure 2: Measured input impedance of kicker with matched output port termination and comparison with $\mathrm{P}$ Spice computations.

Using the equivalent circuit shown in Fig. 3, the P-Spice computed input impedances for the output port terminated in the design $25 \Omega$ are compared with the measured results in Fig. 2. As seen, the agreement is quite satisfactory and establishes the confidence, that dependable predictions of the kicker performance can be made based on the equivalent circuit diagram. Of interest are, for example, the kicker response to a step function voltage, the operation of the kicker with a $20 \Omega$ termination to reduce the voltage requirement, and the estimate of the longitudinal coupling impedance in the frequency range below $100 \mathrm{MHz}$ for which the equivalent circuit is applicable. ${ }^{6}$

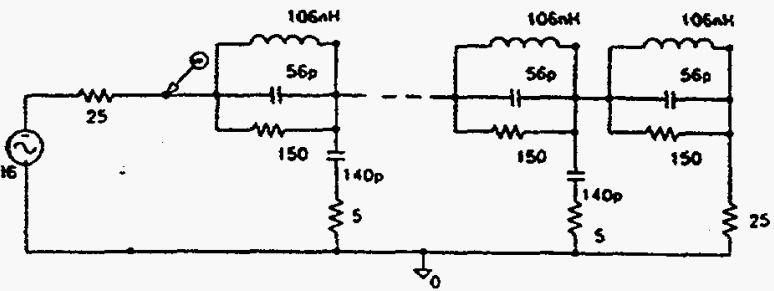

Figure 3: Equivalent circuit of injection kicker. Only 3 of the 14 dielectric capacitors in a full-length kicker are shown.

\section{TIME DOMAIN KICKER PERFORMANCE}

Having established the equivalent circuit based on measurements in the frequency domain, it is now possible to predict the kicker performance in the time domain by means of P-Spice computations. Measurement of the performance of the kicker without beam is effectively limited to the current in the output load. The charging voltage on the Blumlein pulser can also be measured, but its value is not rigorously equal to the input voltage at the kicker.

The kicker load current in production unit \#5 terminated into $25 \Omega$ is shown in Fig. 4 for a $\sim 40 \mathrm{kV}$ pulser voltage, which satisfies the nominal design requirement of 1.6 $\mathrm{kA}$. The measured current is in good agreement with the P-Spice computation. Also shown is the computed "effective kicker current," which renders the rise time of the deflecting force and, neglecting the $3 \mathrm{nsec}$ ion transit time, is obtained by averaging the instantaneous current in the 15 series inductors. The computed rise time of the effective current is $\leq 100 \mathrm{nsec}$ in full agreement with the Sextant Test beam measurements. ${ }^{7}$

The pulse propagation time in the $1.12 \mathrm{~m}$ long kicker was directly measured by means of uncalibrated capacitive probes at the input and output ends. The two signals are shown in Fig. 5; by using a single trigger, the propagation time was directly measured to be $\sim 50 \mathrm{nsec}$, in excellent agreement with the theoretical prediction based on a propagation velocity of $v / c=0.07$. The measured value is also in agreement with the computed P-Spice predictions as seen in Fig. 5, where the the voltages at the input, at the first dielectric block and at the load are shown.

\section{EQUIVALENT CIRCUIT ANALYSIS OF COUPLING IMPEDANCE}

The analytical treatment of the kicker coupling impedance at low frequencies, i.e. below $\sim 100 \mathrm{MHz}$, is instructive but limited and can be complemented with the use of equivalent circuits. ${ }^{6}$ An appropriate model seems to be a multi-cell 

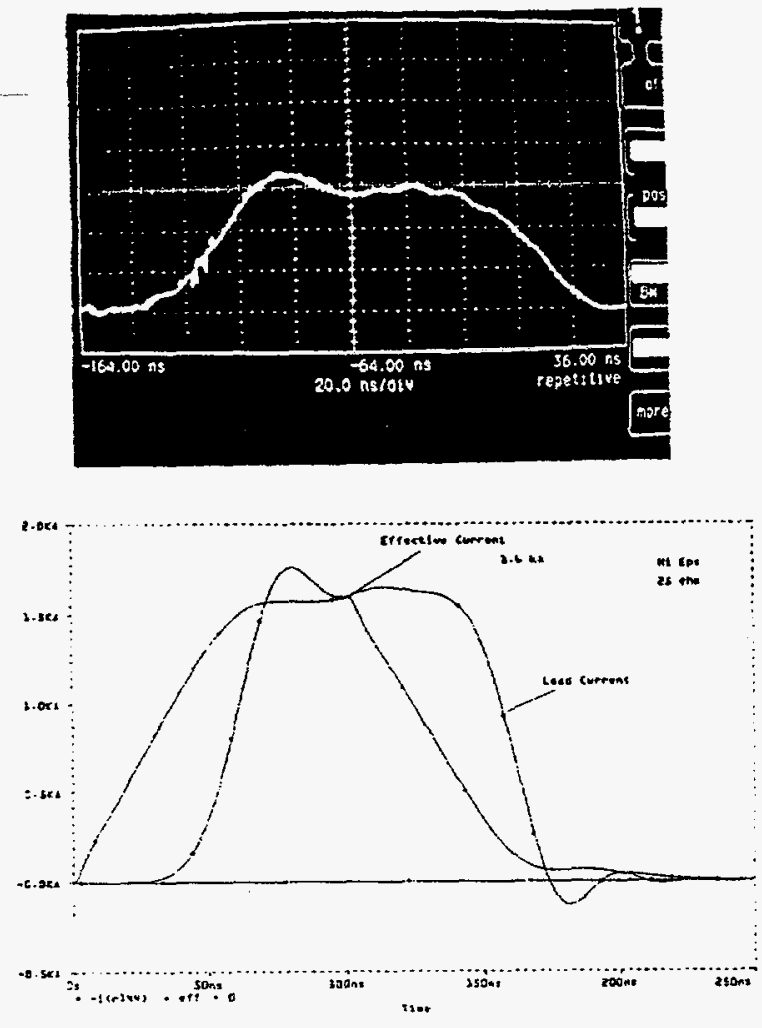

Figure 4: Measured load current at $500 \mathrm{~A} /$ division and comparison with P-Spice computed curve. The computed "effective" current represents the average of currents in the 15 series inductors and is an estimate of the time-dependent kicker deffecting strength.

section low-pass filter with lumped elements, shown in Fig. 6 for a half-size kicker model. Having established the equivalent circuit of the kicker alone, one can add the beam as a series of magnetically coupled inductors, the values of whicl ${ }_{1}$ are determined from impedance wire measurements $L_{B}=18.9 \mathrm{nH}$ and $\kappa=0.82$. The coupling impedance computed by the P-Spice program at low frequencies has been compared with the results from the "wire" measurements. ${ }^{6}$ The agreement is reasonable considering the possible errors in measurement and the limitaiions of the model.

\section{REFERENCES}

[1] H. Hahn, et al. "The RHIC Injection Kicker." (these Proceedings).

12] E. B. Forsyth, et al, Proc. 1995 PAC, Dallas, TX, p. 1921 (IEEE. 1996).

[3] H. Hahn and E. B. Forsyth, EPAC 94 London. vol. 3, p. 2550.

14] H. Hahn. BNL Repon AD/RHIC/RD-66 (1994).

15) H. Hahn and A. Rati. BNL Repor AD/RHIC/RD-112 (1997).
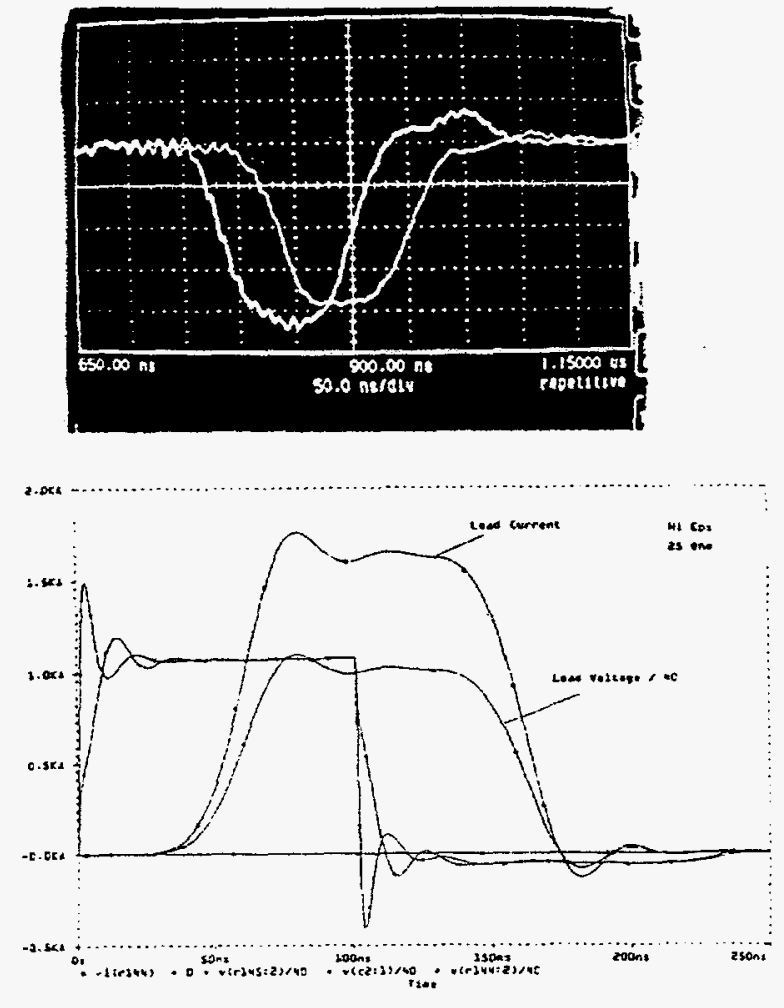

Figure 5: Measured voltage of pulse at input and output end of the kicker. The measured transit time of $\sim 50 \mathrm{nsec}$ is confirmed by the P-Spice computations.

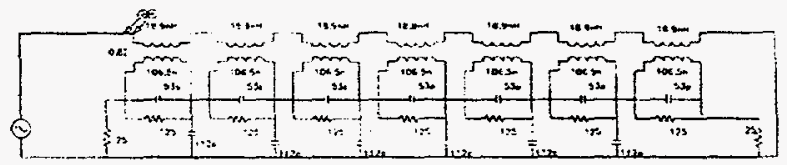

Figure 6: Equivalent circuit representation for the P-Spice computation of the kicker coupling impedance.

16] H. Hahn and A. Ratti, "The Coupling Impedance of the RHIC Injection Kicker System," (these Proceedings). BNL Reports AD/RHIC/RD-105 and AD/RHIC/RD-111.

[7] W. Fischer, H. Hahn, W. W. MacKay, T. Satogata, N.Tsoupas, and W. Zhang. "Beam Injection into RHIC," (these Proceedings). 


\section{DISCLAIMER}

This report was prepared as an account of work sponsored by an agency of the United States Government. Neither the United States Government nor any agency thereof, nor any of their employees, makes any warranty, express or implied, or assumes any legal liability or responsibility for the accuracy, completeness, or usefulness of any information, apparatus, product, or process disclosed, or represents that its use would not infringe privately owned rights. Reference herein to any specific commercial product, process, or service by trade name, trademark, manufacturer, or otherwise does not necessarily constitute or imply its endorsement, recommendation, or favoring by the United States Government or any agency thereof. The views and opinions of authors expressed herein do not necessarily state or reflect those of the United States Government or any agency thereof. 


\section{DISCLAMMER}

Portions of this document may be illegible in electronic image products. Images are produced from the best available original document. 